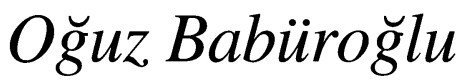

\section{The Vortical Environment}

\section{The Fifth in the Emery-Trist Levels of Organizational Environments ${ }^{1}$}

This paper develops a conceptual scheme to extend the Emery-Trist levels of organizational environments to a fifth level consistent with premises laid in their milestone paper (Emery and Trist, I965/Vol. III). The mounting evidence of maladaptive responses to turbulent environments is the second reason for undertaking this challenge. More specifically, the prevalence of stalemate, polarization, and monothematic dogmatism - the second-order maladaptive responses to the turbulent environment-leads to the frozen or clinched order of connectedness as well as unevenly turbulent conditions. Consequently, a different causal texture of an organizational environment can be added to the previous levels (placed, random; placid, clustered; disturbed-reactive; and turbulent).

\section{Literature Survey Pertaining to a Fifth Level}

Emery and Trist first postulated the possibility of a fifth level of environment as follows:

But there are also unfavorable trends arising from the maladaptive defenses. These are producing conditions to which no adaptation is possible at all. They denote a fifth environment with characteristics of a vortex, signs of which already exist in certain parts of complex societies (Emery and Trist, I973:xiv).

For our purposes, we found it necessary to distinguish only four levels of organization of environments. Any attempt to conceptualize a higher order of environmental complexity would probably involve us in notions similar to vortical processes. We have not pursued this because we cannot conceive of adaptation occurring in such fields. Edgar Allen Poe did go into this problem in his short story "Descent into the Maelstrom." He intuited that there was a survival tactic

'A revised version of a paper in Human Relations, $4 \mathrm{I}: 3, \mathrm{I} 988$. 
if drawn into a whirlpool-namely to emulate an inanimate object. To strive in one's own way was to perish. Folklore and natural history are full of similar lessons about "playing possum" [and] "playing dead." For our purposes we are inclined to regard these as survival tactics rather than adaptive behavior. In case there may be something to the hunch that a Type $V$ environment has the dynamics of a vortex it is worthwhile noting that vortices develop at system boundaries when one is moving or evolving very fast relative to the other-like a Watts County, Los Angeles-and between the developed and underdeveloped countries. (p. 4I)

In their subsequent writings, they did not go beyond these statements, possibly because actual or emerging vortical environments were not numerous enough to warrant directing their interest away from the overwhelming salience of the turbulent world environment of the I960s and I970s. Crombie (I972) had also commented briefly on the vortical environment, suggesting that the environment takes on some of the properties of a vortex or a whirlpool so that it may have the capacity to swallow up or engulf anything that approaches it.

The most promising study to date addressing a fifth type of environment as an extension of Emery and Trist's formulation is that of McCann and Selsky (I984/Vol.III). In it, they discuss "hyperturbulence" as a midrange condition between the turbulent field and the vortical environment. The authors provide a rich array of characteristics that pertain to the transformation stage from turbulent to a vortical environment which the hyperturbulent environment represents. While capitalizing on some of their insight, the intent in this paper is to formulate a conceptual scheme for a vortical environment that goes beyond a discussion of characteristics. There is a firm agreement with McCann and Selsky here that the persistence of turbulent conditions for a long period produces not only active adaptive responses but also a large set of maladaptive responses. They too believe that it is necessary to explore different approaches in extending the Emery-Trist environmental levels beyond the fourth, or turbulent, environment. Emery and Trist (I973) clearly indicate that without conscious, adaptive planning and an active attempt to shape the future, survival will be compromised (Emery, I977/Vol. III).

\section{Adaptive and Maladaptive Responses to Turbulence}

According to Ashby (1960), the system is invariably expected to differentiate to match the variety of its environment. However, differentiation almost always involves the danger of too great an independence of the parts' functions, a circumstance that can lead to disintegration of the system (Angyal, I94I). Resolution of the disintegrative disturbances would have to be addressed not only by the single constituent system but by the involvement of all members of 
the social field. Emery and Trist (I973) refer to this pursuit as active adaptation. Active adaptation to turbulence depends on the emergence of values that have overriding significance for the members of the social field as a whole. Members of the social field will have to seek, design and pursue superordinate values, or ideals, to guide their efforts.

Emery and Trist suggested institutionalization of emergent patterns as the adaptive response that is required. Here, Emery and Trist use Selznick's (1957) conception of institution which is that organizations become institutions through the embodiment of organizational values that relate to the wider society. Therefore, planning in turbulent environments will have to become normative (Ozbekhan, 1969). Only after valued ends and desirable future directions are designed collaboratively can strategies and tactics become meaningful. Emery and Trist (1973) identified the desirable cultural values, organizational philosophies, and ecological strategies that should guide such planning (Perlmutter and Trist, 1986). This emerging logic is also supported by Maruyama (1976), Wojciechowski (1983) and Esser and Gray (1983). Others also stress that adaptation in turbulent environments has to occur in participative, democratic settings (Williams, 1982; Emery and Emery, I977). In sum, we not only understand what to design but also how to manage systems that are immersed in turbulent social fields. However, we do not have a parallel level of understanding for dealing with failures of adaptation to turbulent environments. We need to emphasize the transitional and transformational conditions within turbulent environments to enrich our understanding.

Transformation invariably involves a state of transition, even multiple transformations and transitions. Turbulence places a constituent system in a continuous, permanent state of transition. This notion of continuous transition was also proposed by Schon (I97I), who coined the term "the loss of the stable state." Likewise, Maruyama (1976) observed that we are entering an era of transitions of a different nature, that is, a transition between types of transition that he labeled a meta-transition. Tichy (1983) notes in an organizational context that organizations are perpetually in flux, undergoing shifts and changes.

The effect of turbulence, or a state of permanent transition, on the integrity of a system is relentless. However, such disequilibrating conditions have been shown by dissipative structure theorists (Prigogine and Nicolis, 1977; Prigogine, I980; Gemmil and Smith, I985) to be necessary for transforming system structure into new, more adaptive forms.

Yet the possibility of being locked in the transition state or of failing to make a transition has not been explored. Systems of this kind, caught in the middle of one or more transitions, are stalemated systems. What if a system fails to develop active adaptive strategies in a turbulent field? Despite being turbulent and in a state of disequilibrium, a system that is open to change and able to break down old functions and generate new ones may not occur. Assuming that the rate of failure to adapt to turbulent environments is at least as high as the 
success rate, protracted periods depicted by stalemate may be inevitable. During such a protracted period, internal competition may well create diabolic schisms or polarization. Unable to cope with turbulence, system members turn inward and implode, producing maladaptive responses. In sum, when active adaptive strategies cannot be formulated to cope with turbulent fields, maladaptive responses prevail. We shall argue that these maladaptive responses are predominantly stalemate, polarization and monothematic dogmatism.

\section{CONTEMPorary Evidence}

A brief appreciation of world, national and organizational contexts is necessary to show the salience of stalemate, polarization and monothematic dogmatism. Since World War II, for example, we have been living with a nuclear stalemate (Krepon, I984) among super-powers that has been willingly institutionalized. Behind the screen of deterrence, what Schell (I984) refers to as the "dogmatic truth," we have built the means for our annihilation by providing a logic of mutually assured destruction. The early I 980 s mark the polarization of the international political climate, reminiscent of the worst days of the cold war.

The polarization between the richer industrialized countries and the poorer Third World countries has not changed much since I945 (Ward, I978). Regarding the North-South stalemate (Doyle, I980), the concept of a new international economic order that was brought to the first meeting of the United Nations Conference on Trade and Development in 1964, is now referred to as the old dream of the Third World countries. The ripple effects of Third World debt are threatening all international financial institutions.

The Middle East similarly continues to sustain a number of stalemates, typified by the seemingly endless Arab-Jewish conflict, the seven-year-old IranIraq war and a ruptured Lebanon. As in Lebanon, the people of Northern Ireland are deeply divided along sectarian lines. Cyprus, a focal point of the Greek-Turkish conflict, has been stalemated since I974 (McDonald, I986). There is no immunity from stalemate even behind the iron curtain. Poland, according to Garnysz ( 1984) and Mason (1985), is in a civil-political stalemate in the midst of near economic chaos and the state has not given in to the establishment of a new system of moderate political pluralism. The Afghan war constitutes yet another stalemate (Hyman, 1984) for the Eastern bloc. Cases for stalemate can easily be made for many other nations that are struggling in a transitional phase of their development. Nicaragua, El Salvador, Honduras and Panama in Central America; Cambodia (Chandler, I984), South Korea and India in Asia; and Chad, Zaire (Turner, I985), Mozambique and South Africa in Africa are engaged in stalemated situations sustained with the polarization among parties and actors who tend to believe in or to support their positions in a dogmatic manner. 
Stalemates of different durations can be observed at system levels other than the international and national level. For instance, the city of Chicago, during the first term of Mayor Washington, has suffered as a result of a polarization between the Council majority and Mayor Washington's followers in the Council. Sutton, Eisenhardt, and Jucker (1986) report Atari Inc.'s stalemate between December 1982 and July 1984 during which no significantly new products were introduced. Failure to introduce new products, inability to abandon old practices, intense infighting and adoption of inappropriate business strategies often lead to stalemated situations not only in Atari Inc. but in many other organizations. Stalemates at the organizational level are perhaps more numerous than at any of the other system levels that are mentioned above. Labormanagement conflicts, businesses in declining and stagnating markets and industries, proxy fights, turnaround strategies and bankruptcies could all serve as indicators of potentially stalemated situations (see Babüroğlu, I99I for more examples).

\section{Conceptual Scheme Development Strategy}

Having established the reasons for developing a concept of vortical environments, we can introduce the components of the conceptual scheme to be followed. A theoretical extension of Emery-Trist environmental levels will be proposed starting with the following conditions:

I. The social system persistently fails to develop adaptive strategies to turbulence.

2. The uncertainty and complexity of the turbulent environment is compounded by the prevalence of maladaptive responses, as suggested by Angyal (I94I) and elaborated by Emery (I977/Vol. III).

3. The turbulence becomes endemic and vortical processes predominate, changing the causal texture of the environment.

4. The resulting level $\mathrm{V}$ environment is a theoretically limiting case that should be considered as the counterpoint of the Type I proposed by Emery and Trist ( 1965). Regarding level I, Emery (I977/Vol. III) states:

In postulating random placid environments as one extreme we were well aware that this was largely theoretical. It seems most unlikely that any living system evolved from such environments. (p. 6)

The concept of level V serves the same function as served by the concept of the level I environment. This is not to suggest that the whole of human society will plunge into this state; we are for the moment merely suggesting that new limiting phenomena emerge at the outer edges of turbulence. 
5. The critical assumption made is that there is a different causal texture within the vortical environment, unlike those that characterize turbulent environments. But it should be conceptualized as one dynamic (vortices) forming within a different surrounding dynamic (turbulence). This is also critical to the conceptualization of a vortical environment as defined in this paper. Such difference in the dynamic and causal texture between turbulence and vortices has prompted the possibility of formulating a fifth level in the Emery-Trist framework.

The first component of such a model is achieved by identifying a system of maladaptive responses to turbulence and the second is achieved by showing how the same system of maladaptive responses can be used to formulate the emergence of a new causal texture. Angyal ( I94I) has laid the conceptual foundation for building a systems theory of maladaptation.

\section{Angyal's Thinking on Systems}

Some of the fundamentals of Angyal's thinking are introduced to show Emery's use of his framework as well as to advance a notion of second order maladaptation.

1. To this end, Trist's paper on Angyal is very helpful. In discussing the contribution of Angyal, Trist (1992) pointed out that Angyal made a novel contribution in conceptualizing the interdependence between the system and the environment. Instead of considering them separately, Angyal starts with one, "the universe," which includes both the system and the environment. For Angyal, the life process takes place in the biosphere rather than solely within the organism. Hence, the system and the environment are aspects of the same reality that can be separated only by abstraction.

2. In his analysis of Angyal, Trist points out that for Angyal, organization has a dual character that refers to both structure and process. According to Angyal, a structure is a process and a process has structure.

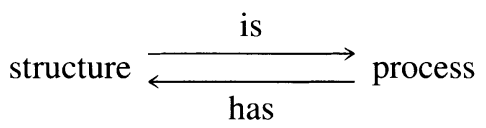

It is the latter sense of process as having structure that is most relevant for us; this is the concept that leads to the structure of biospheric process or of a dynamic whole.

3. The third aspect of Angyal's thinking that needs to be elaborated is the notion of "dimensionality" of dynamic wholes. Angyal (1941) arrives at the dimensionality of dynamic wholes through a discussion of parts. He asserts that "wholes are never entirely undifferentiated but are always structured and 
articulated into parts." He then suggests that the multiplicity of parts is only possible in some kind of dimensional domain. To demonstrate his point, he takes two clear examples of dimensional domains, those of space and time, and states that

... space and time, which have been reorganized by philosophers for a long time as principia individuationis, that is, domains which make possible a multiplicity of individual objects. (p. 249)

The role of the dimensional domain is different from that for space and time in dynamic wholes. The dimensional domain participates in the formation of the dynamic whole compared to serving merely to separate the parts. Using Angyal's example, a comparison can be made between two colors without further reference to space (the dimensional domain). However, Angyal establishes a systemic logic as opposed to a logic of relationships, where the members are connected within and by the whole that exists in a dimensional domain itself. Hence, the dimensional domain serves as a matrix for the arrangement of parts into definite patterns. Angyal uses the term constellations to refer to definite patterns which reflect a specific arrangement of parts in any particular dimension. That the parts are arranged in a system stands in contrast to aggregates in which the parts are added, indicating an entirely different order for the formation of wholes according to Ozbekhan (I97I) who applied Angyal's systems approach to planning. Furthermore, in Angyal's approach, the parts interconnect by means of their position in the whole, not by their inherent qualities.

4. Combining items 2 and 3 above, the structure of a dynamic whole, that is the dimensional domain is, according to Angyal, built around three dimensions: vertical, progression and transverse, which provide a matrix (in the general sense of "something within which something else develops or originates," not to be confused with the rectangular mathematical arrays) for the arrangement of parts. He defines these dimensions as follows.

The Vertical Dimension. The vertical dimension is the depth-to-surface continuum. The surface relates to manifest behavior accessible to direct observation. The depth is the more enduring and the more permanent region of the whole. Angyal (194I) states that:

The depth is more essential and represents what one is, while the surface is more accidental and represents only what one does. Surface and depth are to each other as actuality and potentiality. (p. 266)

As for the connection between depth and surface he remarks

The items along this dimension are so arranged that the one (the more superficial) is concretization of the other (the deeper one). (p. 27I) 
The Dimension of Progression. This dimension is the means-ends organization, that is, teleological organization where each phase in a series of occurrences is the means to the following phase and the end for the preceding phase. In this dimension, the constellation, hence the arrangement of parts, e.g., an occurrence, forms a means-ends organization.

The Transverse Dimension. The transverse, or the dimension of breadth, is one which defines the positioning of the parts standing side by side rather than forming a depth-to-surface or a means-ends organization. The constellation of parts of this dimension forms a synergetic organization or a coordination.

5. Angyal has also developed a theory of disturbances of integration to the organization of dynamic wholes. Although he describes two types of disturbances of integration-interference between systems and segregation-we shall draw on segregation, to be labeled the first order disintegrative disturbance, which he develops far more than the first. Specifically, he defines segregation as the "lack of coherence and of regular communication between systems" (p. 32 I). Segregation is a "disjunction between systems" so much so that the integrative connections to the whole are severed and discontinuities are produced on each dimension. He maintains that when segregation causes a break in the continuity of each dimension, at least three potential outcomes along each of the dimensions are produced-superficiality, segmentation, and dissociation.

These outcomes will be called first order maladaptive defenses. It is important to realize that both the first order and the second order maladaptive defenses - stalemate, polarization, and monothematic dogmatism, to be introduced later-are outcomes of different dimensions in a dynamic whole. These outcomes represent different aspects of the same reality viewed in different dimensions. Therefore, the concepts that are offered do not have to originate from one discipline or from a theoretical tradition. To force them into the mold of an established discipline, such as psychology, or into that of a theoretical tradition, such as structuralism, may amount to losing the meaning of a discourse on dimensions. Given that Angyal applied his systems approach to the study of personality, it should not be a surprise to see the use of concepts (such as superficiality or dissociation) that are borrowed from psychology.

\section{First Order Maladaptive Responses to Turbulence}

Angyal's dimensions of the structure of dynamic wholes and what happens to the system following the disintegrative disturbance can now be explained further. Emery (I977/Vol. III) uses Angyal's theory of disturbances of integration as a starting point for showing the emergence of passive maladaptation to tur- 
bulence which aims to reduce the complexity of social fields. Emery's attempt will also be incorporated in the discussion that follows.

When there is a break in the continuity of the vertical dimension due to segregation, a disturbance of integration, depth and surface become disjointed. As a result of "the break or impairment of continuity of the vertical dimension, surface manifestations no longer express deeper tendencies and thus become more or less empty" (Angyal, I94I:323). This he calls "superficiality." Hence, the outcome as a result of the disturbance on the vertical dimension is called superficiality by Angyal. In Emery's (I977/Vol. III) elaboration, it is increased indifference to what needs or demands are taken as a starting point for one's behavioral responses. As a passive adaptive response to turbulence, it constitutes a tactical retreat from an environment that is seen as too uncertain and too complex to cope with. The relevant uncertainty generated by turbulent environments leads to an attempt to reduce it by being indifferent or by denying the reality of the deeper roots of humanity that bind social fields together.

Disintegrative disturbance in the progression (means-ends) dimension is when an activity is aborted before completion. Thus, means and ends become loosely connected, if at all. The aspect of disintegrative disturbance in this dimension, Angyal pointed out, involves separation of means and ends, whereby the subordinate goals become independent and lose contact with the main goals of the activity. Emery labeled this type "segmentation"; the social field is transformed into a set of social fields each integrated within itself and pursuing a goal, but each poorly integrated with the others. When there are no reintegrative or reconstructive processes, simplifying environments into segments of manageable size in this way becomes maladaptive. Emery attributes segmentation to escape from the demands of choice.

The impact of the disintegrative disturbance on the transverse dimension is manifested by a lack of coordination between the parts in the whole. Discontinuity in the transverse dimension is called "dissociation." Emery describes this form of passive adaptation as a retreat into private worlds and a withdrawal from social bonds that might entail involvement in the affairs of others. Hence, it is a reduction in the willingness to coordinate one's behavior with that of others or to allow one's actions to be regulated by the behavior of others. It is also a denial that another's world and reality are relevant and that shared values exist between oneself and others. Consequently, no commitments are made beyond what is considered to be one's own.

It is important to delineate Emery and Trist's conclusions with regard to the three maladaptive responses:

I. They are mutually facilitating defenses (against turbulence), not mutually exclusive.

2. They all tend to fragment the spatial and temporal connectedness of the 


\section{I 2 Conceptual Developments}

larger fields and focus further adaptive efforts on the localized hereand-now.

3. They all tend to sap energies that are available to and can be mobilized by the larger systems and otherwise reduce their adaptiveness.

Superficiality, segmentation and dissociation are interdependent maladaptive defenses. For example, when segmentation allows groups to form without much regard to the goals of the system of which they are a part, the newly formed groups are dissociated from other groups and are not interested in coordinating their efforts with them.

Crombie (I972/Vol. III) introduced the passive and active distinction into the discussion of maladaptive responses. Active maladaptation is suggested as the logical correlate of the passive response. In other words, Crombie claims that following a disintegrative disturbance such as segregation and the subsequent failure to achieve a satisfactory level of integration of each of the three dimensions, an active maladaptive response can result as well as or instead of a passive maladaptive response. Crombie introduced a further distinction by claiming that a passive response serves as a defense against turbulence and an active one serves to reduce the uncertainty and complexity of turbulent environments.

Synoptic idealism is the correlate of superficiality at the vertical dimension. While superficiality constitutes a defense from the turbulent environment through a reliance on criteria only too familiar to a system typified by custom and convention, synoptic idealism attempts to cover every piece of relevant occurrence in a comprehensive manner to control and reduce the causal texturing to a disturbed-reactive lower level. As opposed to superficiality, its focus is with depth. Crombie points out that

The limits of men's intellectual capacities, the multiplicity and fluidity of values and the prohibitive costliness of information gathering are just some of the reasons why synoptic idealism is in practice impossible to sustain for complex situations. (I972: 147)

The passive maladaptive response to the disintegrative disturbance at the means-ends progression dimension is manifested either as a breakdown or segregation between the parts' pursuit toward the ends of the parts or toward the ends of the whole. Authoritarianism, which is the active maladaptive response, comes about as an attempt to make sure that there isn't or there won't be any breakdown in the means-ends or part-whole relationships by imposing a very rigid structure. Parts are coerced into being subordinate to the ends of the system as a whole through the use of power and in the name of law and order.

Crombie claims that at the lateral dimension, the logical correlate of dissociation, is evangelism. The domination of autonomous tendencies leads to dis- 
sociation, and the domination of homonymous tendencies leads toward evangelism. Crombie (1972/Vol. III) states that:

The term evangelism is used because it is evocative of such notions as "all pulling together" and entering into brotherhood as responses that are appropriate to the solution of personal bewilderment or disengagement. (p. I52)

\section{Second Order Maladaptive Responses to Turbulence}

In this section, we will try to extend the discussion of maladaptive responses to another phase characterized by the prevalence and persistence of the aforementioned maladaptive responses. Using the basic three dimensional representation of a dynamic whole, we can imprint the first and second order maladaptive responses and disintegrative disturbances. The second order maladaptive responses are of a higher order and subsume the first order maladaptive responses. This means that as in the differential equations, the first derivative (order) is theoretically derivable from the second and vice versa. The same kind of qualitative but intrinsically connected difference between the first and second order maladaptive responses is implied here. Dogmatism, for example, a second-order maladaptive response, subsumes superficiality the same way acceleration subsumes velocity.

While the need to design active adaptive strategies quickly and expeditiously by the constituent systems of the turbulent social field is great, the very nature of active adaptive strategies can present a counterdynamic to this urgency. The development and acceptance of shared values and institutions are lengthy and slow processes. This point is also made in McCann and Selsky ( $1984 / \mathrm{Vol}$. III) and could be one reason for the persistence of maladaptive responses. The emergence of alternatives to bureaucracy, namely democraticparticipative forms, might be impeded by the bureaucracy itself. Centers with vested interests would probably not surrender their power and control to make participation feasible. Revolution in communication, as it is expressed through television, might fuel maladaptive responses such as dissociation (Emery and Emery, I977/Vol. III) and thus lead to the perseverance of this maladaptive response.

The constituent systems that are of interest here are those that are consistently failing. There is an abundance of references to failing or declining organizations in the literature (Hannan and Freeman, 1978; Platt, 1985; Olson, 1982; Whetten, I980; Miller, I977). The constituent systems consistently fail in formulating adaptive strategies or recognizing the existence of turbulent environments and, hence, continue to resort to passive or active maladaptive 
strategies. In the wake of this behavior pattern, crystallization of the aforementioned maladaptive responses is likely to materialize. These are referred to as the second-order maladaptive strategies. While first order maladaptive responses attempt to reduce the causal texture, the second order maladaptive responses crystallize it. At this juncture, the characteristics of stalemated social systems become relevant and would comprise the second order maladaptive responses. The persistence and crystallization of maladaptive responses along the vertical dimension will convert superficiality or synoptic idealism into dogmatism; along the dimension of progression, it will convert segmentation or authoritarianism into stalemate and along the transverse dimension, it will convert dissociation or evangelism into polarization.

At this stage, there is a change in the nature of the disintegrative disturbance. Angyal (I94I) referred to segregation as the disintegrative disturbance which is being labeled the first order. Whereas segregation would lead to separation of the parts for some purpose, fragmentation, the second-order disintegrative disturbance, rips the whole apart. Parts are broken off in such a manner that the whole becomes unrecognizable. They can be thought of as parts of a lost or destroyed whole resembling the broken pieces of a pane of glass. As suggested by Hedberg, Nystrom and Starbuck (I976), fragments flying outward at different speeds cannot be restrained, diverted or reintegrated in a dynamic way. Fragmentation is, therefore, a tendency to split and break up into parts along almost arbitrary lines and the intensification of fissiparous tendencies within a system/environment. The proposition is that fragmentation results from an implosion of the system which is the act of bursting inward. The fragmented parts are not able to develop sufficient platform and institutional strength to establish the new rules of the game which can provide the new integrating framework and alleviate the disintegrative disturbance.

Two points need to be made before we embark on delineating the secondorder maladaptive responses. First, the concepts that constitute the secondorder maladaptive responses - stalemate, monothematic dogmatism and polarization-are not necessarily new; these are concepts well grounded in the social, political and psychological sciences. However, they do gain new significance, attention and additional meaning in the context of vortical environments. Second, the crystallization of maladaptive responses does not make them mutually exclusive. They remain mutually facilitating responses. It may be possible to take each maladaptive response and show the strands of dogmatism, polarization and stalemate in it or, indeed, it might be possible to construct other maladaptive responses of the second order (see Babüroğlu, 1987).

I. Monothematic dogmatism. In the vertical dimension, scholarly attention is being given to the separation of depth and surface. Superficiality, the firstorder passive maladaptive response, was described as the denial of depth. Synoptic idealism, the active maladaptive correlate, was taken to be a compre- 
hensive sweeping of depth. In dogmatism, depth is captured once and for all. It is a superficial satisfaction of the need for overriding values to guide behavior in turbulent environments. Hence, dogma becomes the normative base for distinguishing right from wrong, good from bad, goals from noxiants. The relevant uncertainty is replaced by "crystal clear truth," which might be called a closed system perspective to truth and reality. The thinking and the outlook become dogmatic in a monothematic society. Whereas a polythematic society is one that is free, tolerant, fluid and pluralistic, a monothematic society is one that is committed to the same theme and that cannot go beyond it. Theocratic or proletarian states are examples of monothematic societies. It is sufficient for the members of a system to be dogmatic for monothematic dogmatism to prevail as the dominant maladaptive response, even though the whole system may not fit this description.

If Rokeach's (1960) definition of dogma is matched with our conception, a workable definition for our purposes would be as follows: dogma is encapsulated reality that contains the absolute truth, beauty, and utopia bounded by a closed cognitive organization of beliefs. It implies a state of ideal perfection pertaining to the omnipotent guide, the supernatural force, the political party, or the scientific or intellectual belief system and attracts a following of "true believers" who deny the individual psyche and believe in only one espoused pattern of connections with social fields. Hofer describes this mind-set as follows:

To be in possession of an absolute truth is to have a net of familiarity spread over the whole of eternity. There are no surprises and no unknowns. All questions have already been answered, all decisions made, all eventualities foreseen. The true believer is without wonder and hesitation. "Who knows Jesus knows the reason of all things." The true doctrine is a master key to all the world's problems. With it the world can be taken apart and put together. (p. 77)

The master key, that is, the self-contained absolute truth, is taken to be the one and only way to resolve problems of system integration and differentiation. The notion of this absolute truth spreading over the whole of eternity is also reflected in Lifton's ( I979) argument. Lifton claims that cultural dislocation creates a struggle to overcome collective deadness and reassert connectedness with a larger whole. Similarly, dogma serves the function of trying to reassert connectedness with a larger whole as a result of fierce and continuing disintegrative disturbance and with the possibility of snapping all ties with the environment. The fear and anxiety of getting stale and of discovering a perfect means of escaping from the death of the system are integral components of dogmatism.

2. Polarization is a second order maladaptive response that represents crys- 
tallization at the transverse (breadth) dimension. Dissociation, a passive maladaptive response to turbulence, indicates a lack of coordination of parts with each other and with the whole. Dissociation depicts a social field ridden by parts that are neutral, to the point of not being interested or not caring, toward each other and toward the whole. The parts are hanging loose, distributed almost in a random manner reminiscent of a Type I environment. In polarization, the parts are charged, positively toward some, and negatively toward others. When they are positively charged, they form social enclaves in the sense intended by Selsky and McCann (I984/Vol. III), but maladaptive ones. These enclaves, which are cohesive and well-integrated in themselves, provide the individual members with norms and values consistent with their perception of honor, justice, and loyalty. Most of all, a feeling of belonging or community, or an expression of the trend toward what Angyal called homonomy. Toffler ( 1980 ) equates retracking to enclaves with being human again. As such, the ingroup members will strive to surrender themselves and become an organic part of something that they consider greater than themselves, a supra-individual and supra-ordinate whole.

If the whole system is disintegrating and there is no countermechanism for reintegrating the fragmented parts through a process of synthesis, parts (or groups) will depend on the existence of other parts (or groups) for their identity. Simmel's ( 1955) insight into the function of conflict is very useful at this juncture because it is through conflict that the parts in a social field are said to be charged. Simmel holds that conflict sets boundaries between groups within a social system by strengthening group consciousness and awareness of separation, thus establishing the identity of the group. An in-group defines itself by struggling with other groups, particularly in the absence of an integrating framework. Simmel called these other groups "out-groups" and Newcomb (I950) labeled them "negative reference groups." In in-group/out-group dynamics, which we take to be characteristic of polarization, both trends of what Angyal (I94I) referred to as autonomy and homonomy are expressed. The tendency at the group level is autonomy, exemplified in each group's striving to become more distinct and independent from others. The tendency at the individual level is homonomy as a need to belong to a larger whole, satisfied through the strong affiliation with an in-group. Furthermore, the in-groups serve the same function that evangelism advocates; Crombie's first-order active maladaptive response is subsumed under polarization.

The significance of out-groups in terms of formation of the group identity and distinctiveness is a special kind of paradoxical interdependence. The very fact that a group $A$ is being opposed by another group $B$ within the same social system helps to determine further its distinctiveness and integrity. Therefore, polarization may imply a limited interest in the survival of the other party, particularly under stalemated conditions. 
The in-group/out-group dynamic, which views the world in terms of us and them, is very destructive to the system's performance overall and thus is selfdefeating. Coupled with a dogmatic style, it reduces the complex intertwining of reality to the most simplistic level, into black and white or god and devil terms. In behavioral terms, the social system's behavior regresses to a basic "attack and defend" posture due to polarization. It is a given that all moves and countermoves made by the opposing party are suspect. Rationales for interpreting and justifying any moves as evidence of a malevolent strategy are in endless supply.

Nieburg ( I969) makes the following point:

The culture of "push and push back" exists to some extent in all walks of life but it becomes legitimate in the absence of higher legitimate normative systems of behavioral forces. . . . Vendettas, clan and tribal murder, feuds-all the common forms of low grade warfare-become daily means of life, the legitimate manner of conduct, the model for normative values and the only means of working out relationships. (p. 85)

3. Stalemate is crystallization in the dimension of progression. The first difference in the characteristics of the second order maladaptive response is the existence of perceived or imminent power parity or leverage to develop power parity among the parts. Segmentation and authoritarianism, first order passive and active maladaptive responses, were not meant to imply equal power among the parts and equal capacity to act or to try to impede the efforts of others. Emery's (1973) elaboration of segmentation rested with the differentiation of the social field so that the segments (parts) can become more autonomous with respect to the whole social field. The active maladaptive counterpart, authoritarianism, implied an all-powerful whole to which the parts are definitely subordinated. Owing to the intrinsic or potential power parity, stalemate is neither of the above, and this is why it has to be considered as a different order of maladaptation.

In ordinary use, stalemate connotes the suffocation or frustration of progress, movement, growth, or development for the whole system. It signifies a state in which there is a perpetual lack of change in the adaptive capacity of the whole social system and its ability to cope with turbulent environments. What distinguishes stalemate most, however, is its inability to articulate, design, and in particular, pursue sometimes even the most mechanical ends of the whole system. There seems to be an obsessive concern with the means at almost complete expense to the ends, so much so that stalemated social systems come as close to being purposeless as can be expected from a social system which is purposeful by definition (Ackoff and Emery, 1972). Metcalfe (1978) refers to a "productivity trap" and Maruyama (1982) to a "goal moratorium" to capture 


\section{I 8 Conceptual Developments}

a similar notion. In this study, Jean-Paul Sartre's conceptualization of absurdity as means without ends is adopted to show discontinuity in the means-ends organization. Decomposition of the turbulent social field into parts would be a viable strategy if the trend toward autonomy was matched with higher-level integrative processes. However, the pursuit of autonomy without regard to the whole social field or the social system is maladaptive. Disregard of the part-whole interdependence, as in stalemate, inevitably contributes to the means-ends discontinuity where the activity of the parts, guided by their own purposes, does not contribute toward the process of attaining some end for the whole system. The second-order maladaptive response becomes pronounced when parts develop an accentuated tendency to oppose each other (rather than joining together to serve the whole) in addition to opposing the whole.

In the next section, we will elaborate the proposition that the set of second order maladaptive responses are the main contributors to the emergence of a vortical environment. Dogmatism, stalemate, and polarization are active responses in the sense that they emerge as remedies to the perplexity of turbulent environments. Since very strong forces can be generated by the dynamics of polarization, dogmatism, and stalemate, we consider it impossible to formulate a set of second-order passive maladaptive responses.

\section{The Construction of a Fifth Level in the Emery-Trist Levels of Organizational Environments}

It is crucial to articulate clearly the implicit assumptions underlying the organizing principles, the building blocks, the unit of analysis of the Emery-Trist framework, and the connections between Angyal's dimensions and EmeryTrist components of open systems behavior to construct an extension of the four levels of environments they have identified. Emery and Trist (I965/ Vol. III) identified four ideal levels of environments in increasing order of complexity and connectedness and in increasing degrees of causal texturing.

The articulation of the correspondence of the Emery-Trist model of an open system and Angyal's conceptualization of a dynamic whole is crucial for our theory-building efforts since we are interested in using the second-order maladaptive responses derived from Angyal's conceptualization to extend the Emery-Trist environmental levels to a fifth one.

\section{Organizing Principles}

The increasing order of complexity and connectedness and the increasing degree of causal texturing are taken to be the two fundamental organizing principles of the environmental levels. 
Increasing order of complexity and connectedness. Complexity for Emery and Trist expresses the richness of the environmental texture. Although this is a concept they have not formally defined, it is assumed here to mean the number of new or possible linkages, the emergence of new domains and interdependencies. Environmental or systems connectedness as used by Emery and Trist is a means of decoding, discussing or referring to complexity. When they assert that "complexity is greater than that which we have learned to cope with," they refer to the way in which connectedness is manifested within environments.

Increasing degree of causal texturing. Causal texture determines in what sense and to what degree the environment is organized or structured. The concept of causal texture is spelled out by Emery and Trist (I965/Vol. III; I973).

By causal texture we meant, following Pepper, Tolman, and Brunswick, the extent and manner in which the variables relevant to the constituent system and their interrelations are, independently of any particular system, causally related or interwoven with each other. (p. 4I)

In this explanation, causal texture is defined with two identifying characteristics: (I) the interwoven variables relevant to the constituent system and (2) the interrelations of the constituent system. In expanding on the first, Emery and Trist explain that

For simplicity of exposition we considered the relevant variables only as goal objects or noxiants for the constituent system (i.e., having different relevant values for the system with values ranging from positive to negative) and assumed that there is some sense in which these can be spoken of as more or less distant from or available to the organization and hence requiring more or less organizational effort to attain or avoid. (p. 4I)

Emery and Trist further define goals as those parts of the environment that have a good and desirable influence on the organizational behavior, and noxiants as having a harmful influence on it. When they begin to conceptualize the relevant variables as parts of the environment, it becomes much easier to link "relevant variables" to Angyal's notion of an "arrangement of parts." Thus, it is the arrangement of goals and noxiants that are valued or devalued by the constituent system; like the arrangement of threads in the texture of some material, they make up the causal texture of environments.

The second way of characterizing the causal texture through interrelations turns out to be much more rigorous when Emery (I977/Vol. III) begins to use "interrelations" and "interdependencies" interchangeably. Since Emery and Trist's original conceptualization of open-system behavior, rested on the con- 
cept of interdependency, the classification of environmental levels based on increasing degrees of causal texturing can now be demonstrated with more clarity.

\section{BUILDING BLOCKS}

It has become a convention to start a discussion of organizational environments by quoting from the I965 Emery and Trist paper to establish the "formal" language with which to talk about organizational, open-system or purposeful behavior (Terreberry, I968; Williams, I982; Emery, I977; Trist, I980; Burns, I983; Schoderbeck, Schoderbeck, and Kefalas, I985).

... we may now state the general proposition: that a comprehensive understanding of organizational behavior requires some knowledge of each member of the following set, where $L$ indicates some potentially lawful connection, the subscript I refers to the organization and the subscript 2 to the environment:

$$
\begin{array}{ll}
L_{11} & L_{12} \\
L_{21} & L_{22}
\end{array}
$$

Here $L_{11}$ refers to processes within the organization - the area of internal interdependencies; $L_{12}$ and $L_{21}$ refer to exchanges between the organization and its environment - the area of transactional interdependencies, from either direction; and $L_{22}$ refers to processes through which parts of the environment become related to each other, that is, its causal texture - the area of interdependencies that belong within the environment itself. (Emery and Trist, I965/Vol. III, p. 54)

These connections, $L_{11}, L_{21}, L_{12}$ and $L_{22}$, are referred to as intra-input, output and extra-system interdependencies by Terreberry (1968) and as system processes $\left(L_{11}\right)$, learning processes $\left(L_{21}\right)$, planning/instrumentality processes $\left(L_{12}\right)$ and environmental processes $\left(L_{22}\right)$ by Emery (Emery and Trist, I973), who also indicates that planning and instrumentality are forms of interpenetration of the system into the environment and that learning serves as an interpenetration of environment into the system. He suggests that the latter should be viewed as (I) the informational structure of different environments and (2) the kinds of behavior in these environments that justify the title of "learning behavior."

The causal texture is, in turn, determined by combinations of these four kinds of interdependencies. This is the second characteristic of the concept of causal texture, as discussed above. The four kinds of interdependencies are considered to constitute the building blocks of the Emery-Trist framework. In 
fact, using the second characteristic of causal texture, Emery (I977/Vol. III) constructed the following ladder of environmental levels:

$\begin{array}{ll}\text { Placid, random } & L_{11} \\ \text { Placid, clustered } & L_{11} L_{12} \\ \text { Disturbed-reactive } & L_{11} L_{12} L_{21} \\ \text { Turbulent } & L_{11} L_{12} L_{21} L_{22}\end{array}$

\section{UNIT OF ANALYSIS}

Thus far, in developing the ideal levels of environments consistent with the organizing principles and the building blocks, the unit of analysis has not been explicitly stated. Yet, in another discussion, Emery and Trist (I973) describe the unit of analysis as one which "must include the system and its immediately relevant environment." For them, the unit is the "social field," which they define as follows:

In populations of living systems capable of active adaptation, each system is part of the environment of the others and they constitute together a social field. (p. I8)

This unit is very similar to what Angyal called the biosphere (the universe that contains both the system and the environment) with one difference, namely, that the social field includes less than the total environment of a system (Emery and Trist, I973: 19). The difference is not very significant to understanding how the levels were constructed. What needs to be recognized is that the unit of analysis includes both the system and at least its relevant environment. This means that the Emery-Trist levels of organizational environments are constructed at a higher level of abstraction than the system and its environment. Implicit in Emery and Trist, the higher level of abstraction termed "the organizational environment" that contains the system and its environment, is the unit of analysis.

\section{The Connection Between Angyal's Dimensions and the Emery- Trist Components of Open-System Behavior}

There is a correspondence between Angyal's dimensions of a dynamic whole and the components of open-system behavior as defined by Emery and Trist which was not made explicit before. Lawful internal interdependencies, the $L_{11}$ relations, belong to Angyal's conceptualization of the transverse dimension. 
Emery (I977/Vol. III) regards $L_{11}$ as dependent to some degree on how the parts of the system pull together, and as a relation of part to part within a whole. This is very similar to Angyal's definition of the transverse dimension of a dynamic whole, which is expressed by the positioning of the parts standing side by side to form a synergetic organization or a coordination.

The transactional interdependencies between the system and the environment, $L_{12}$ and $L_{21}$, Emery and Trist considered to be what the system can do in its environment and the interpenetration of the environment into the system, respectively. The $L_{12}$ relation, according to Emery and Trist (I973), refers to the actions of a purposeful system where the system has the ability to choose desirable means in any given situation to obtain desirable ends. This unambiguously refers to the dimension of progression of Angyal which is the means-ends organization within a dynamic whole. The $L_{21}$ relation encompasses what Emery (Emery and Trist, I973/Vol. III) called learning, that is, learning about the processes within the environment. To Emery (I 977/Vol. III; I98I) learning is the ability to perceive deeper orders of invariance and to see patterns, relationships and context. The parallel between this conceptualization and Angyal's vertical dimension which he considers as the depth-to-surface continuum is also quite evident.

For $L_{22}$, the interdependencies that constitute extended social fields, there isn't an immediately obvious correspondence with Angyal's dimensions of a dynamic whole. However, a case can easily be made that there isn't a contradiction in Angyal's conceptualization. Each dimension in Angyal's conceptualization of a dynamic whole is constructed as a constellation of parts. We could infer that the parts not participating in the formation of the dynamic whole do, indeed, participate in the formation of other similar or dissimilar wholes whose presence, influence, and interactions create the extended social fields, namely $L_{22}$.

At this juncture of the theoretical journey, the conceptual tools for constructing a fifth level of organizational environment are before us. The task now is to combine the conceptual tools with the second-order maladaptive responses to substantiate the fifth level.

\section{The Fifth Level: The Vortical Environment}

Given this background, we can now begin to consider the addition of the vortical environment as a new phenomenon to the Emery-Trist levels of organizational environments.

To show how it is added, we must utilize the organizing principles of the Emery-Trist taxonomy. These are, as mentioned earlier, the increasing degree of complexity, connectedness and causal texture. Given these organizing prin- 
ciples, the addition of a fifth level must satisfy the criteria of an ultimate degree of complexity, connectedness, and causal texture where no more interdependence or connectedness can be added. Therefore, ultimate degree of complexity is reached when the environment cannot be made more complex and, because there is no more room for additional complexity, becomes rigid, clinched and frozen. To appreciate how the structuring or the organization of the new environment becomes frozen, it is important to remind ourselves that we are considering a situation in which maladaptive responses of the system to the turbulent environment persist. We have identified the persistence of maladaptive responses to have reached a second and also a higher level of ordering. These second-order maladaptive responses, as suggested above, are polarization, stalemate and dogmatism. It is these maladaptive responses that lead to a rigid and frozen structuring or organization of the environment.

Owing to the correspondence of the aforementioned second-order maladaptive responses (derived from Angyal's dimensions of a dynamic whole) to the three components of the Emery-Trist open-system model, we can conclude that what in fact freezes or rigidifies are the three components: $L_{11}, L_{12}$ and $L_{21}$. Polarization freezes $L_{11}$, stalemate freezes $L_{12}$, and dogmatism freezes $L_{21}$ interdependencies. The turbulent environment generated by $L_{22}$ still persists as a result of maladaption but nevertheless continues to produce dynamic and unexpected changes. The vortical environment generates, therefore, not only as a consequence of the persistence of maladaptive responses but also due to the persistence of turbulent conditions and, as such, may be considered analogous to the "black hole" phenomenon in astrophysics. The fifth level can now be added to Emery-Trist's four levels of organizational environments:

$\begin{array}{ll}\text { Placid, random } & L_{11} \\ \text { Placid, clustered } & L_{11} L_{12} \\ \text { Disturbed-reactive } & L_{11} L_{12} L_{21} \\ \text { Turbulent } & L_{11} L_{12} L_{21} L_{22} \\ \text { Vortical } & \boldsymbol{L}_{\mathbf{1 1}} L_{\mathbf{1 2}} \boldsymbol{L}_{\mathbf{2 1}} L_{22}\end{array}$

In this fifth level of causal texturing, goals and noxiants are charged positively and negatively. Some are strongly valued and some disvalued by constituent systems. Thus, the fabric is polarized; its parts violently oppose each other and the whole. In comparison with the other four environmental levels, which were discussed above, the structuring of vortical environments could be described as clinched or frozen connectedness. Ashby's (I960) richly joined system becomes crystal-like when there is no or zero degree of freedom in the way parts are connected. As in chess, stalemate characterizes a fixed positioning of all the parts on the board so that no legal move can be made, and the requisite variety of outcomes that correspond to each move is kept exactly the 
same for both parties. Each piece has to be checked, immobilized, for the game to be stalemated. In social systems, it is the specific sequence of communication between the parties that has the effect of preserving the state of stalemate (Hirschhorn, 1978).

Polarization is what governs the interaction between the actors so they can make a move or a countermove to sustain the stalemate. The manner in which one party engages in such activity can only serve to block any move of the other party that might bring them closer to winning. The causal patterning is already learned, since it would be a regression to give supremacy to a most familiar and fundamental animal instinct, that is, the desire to attack and defend. As a reduction of probability of choice, the learned behavior would be to interpret every single event and activity as initiated by the other side with the purpose of harming one's own group. This defensive posture would naturally lead to blame and recrimination, followed by action either to prevent the perceived harm, or to harm the other group. Hence, survival depends on the ability to attack and defend with whatever means necessary. The "us-them" syndrome obliges every suggestion and action to be considered with suspicion and bad intent, a characteristic of common paranoia.

The desired outcome, whether consciously or unconsciously formulated, is to keep the other party from winning or making a move that goes unchecked. Planning, therefore, occurs exclusively to regulate the internal interdependencies and is aimed at obstructing the other constituent parts from reaching their objective. As a consequence of its warring parts, the whole system's performance and progress suffers. The us-them syndrome and polarization continuously inhibit an outcome or end for the whole system to emerge. Hence, the social system appears purposeless as a result of the denial of both transactional interdependencies, $L_{12}$ and $L_{21}$, in which parts act with reference to other parts and not to change the social field that might dissolve stalemate.

In the absence of effective management of transactional interdependencies, a probable failure to distinguish between the system and its environment comes to the fore. The parts can establish their boundaries through conflict with other parts and maintain an identity defined at least as being different from the other parts. Yet, internal conflict does not help the whole system to maintain a boundary unless it can itself engage in conflict with other systems.

Stalemated social systems are characterized by a lack of purpose or the absence of a shared image of the future for the whole system. We postulate that owing to an inability to manage transactional interdependencies, there is mutual interpenetration between the system and the environment.

In the near absence of transactional interdependencies, the turbulent environment and the relevant uncertainty wash over the system, and the messages that originate from the environment are very confusing to the members of the system who are willingly or unwillingly caught up in the process of polariza- 
tion. A value system is adopted as would be expected under the turbulent conditions, although it is one that seeks to resolve, once and for all, uncertainties and tensions of the past, present, and future. This is why the polarized parts resort to dogmatism to alleviate the confusion and the pressures of choice. As such, metaphorically speaking, dogma is an attempt to freeze turbulence. Furthermore, dogma has a fixed, unchanging, binding and authoritarian quality, so that dogmatic beliefs seem to be closed to the process of correction and revision that characterize other areas of belief. Hence, the implications of dogma with respect to learning are rather clear. Metcalfe (I982) also noted how some closed ideologies can impose rigidities of perception and interpretation and, by putting some assumptions beyond discussion, obstruct the process of adaptation.

Finally, all three second-order maladaptive responses, stalemate, polarization and dogmatism, create a "sealing off effect" in which the system has manifestly (but not in reality, since $L_{22}$ continues to generate changes) insulated itself from the nature and impact of the turbulent environment. A paradox is apparent here because, despite the second-order maladaptive responses to eliminate turbulent conditions, turbulence generated by $L_{22}$ has not been eliminated.

When the system is so sealed off from the environment that transactional interdependencies are almost nonexistent and the system's parts have effectively immobilized each other, the causal texture of the environment can no longer be considered turbulent. At this juncture, the causal texture has effectively become vortical.

\section{Conclusion}

How is it that notions of rigidity and determinism connoted by stalemate, monothematic dogmatism, and polarization go together with notions of very strong and unexpected change, uncertainty, and complexity in turbulent environments? How is it that vortical environments are characterized by clinched orders of connectedness and yet can be subject to fluctuations and chaotic and disorderly change? How is it that stalemated systems are highly differentiated as well as highly integrated at the same time, as Hirschhorn (I978) observed?

In constructing a fifth level of organizational environments, we are concerned with a system that is attempting to seal itself off through the processes of stalemate, polarization and dogmatism from environmental influences and impacts. This attempt comes about not only as a defense but also as a result of trying actively to cope with an environment gone turbulent. In this sense, they are active maladaptive responses. Feedback control loops, or, in the EmeryTrist terminology, transactional interdependencies that make adaptation to a 
changing environment possible through self-regulation and self-direction diminish to a very ineffective level and isolate the system from the environment in which it is expected to survive.

The more the system attempts to seal off and dampen the turbulence, the more it gets out of kilter and misaligned with respect to the environment. The greater the misalignment with the environment, the less it can depend on the environment for the energy and information it needs to renew itself (Gemmil and Smith, 1985). The more the system tends toward becoming a closed system, the more entropy it produces (Buckley, 1968). The increase of entropy production renders possible the appearance of new instabilities (Prigogine and Nicolis, 1977). The transactional interdependencies that support learning and planning are dislocated and redirected inward, becoming interdependencies to be utilized in the polarization process by the parts to effectively lock the system. Energies are expended within the system and are not used to manage the viability of the system within the environment. Without the transactional interdependencies, the system gets stale and begins to wither away. Thus selfsealing or, more appropriately, self-defeating processes such as stalemate, polarization and dogmatism can lead to more instabilities, changes and fluctuations.

Prigogine (1980), in his Nobel Prize winning work regarding chemical reactions, presented a medium of instability and disequilibrium in which chemical reactions take place and described that medium as having a deterministic and a stochastic character. He thus proved that both are necessary for the genesis of dissipative structures. For another example of dual explanations which are contradictory, the collusion and co-occurrence of wave and particle movements in physics can be cited as a well-accepted phenomenon. Similarly, in social systems, rigidity and change can be expected to co-occur. Vortical environments are produced by processes connoting rigidity and closure and those connoting change and instability.

On the one hand, the system mirrors the variety and the differentiation of the environment as a result of its implosion and fragmentation (the fissiparous tendency to which the system is subject is referred to earlier in the discussion as a second-order disintegrative disturbance). On the other hand, the variety is consumed by the self-sealing processes of stalemate, polarization and dogmatism.

Polarization serves as a means of relating to the foreign elements as well as a device for strengthening the in-group by serving as an identity reference. Hence, it acts as a means of integration for the fragmented parts, positioning them with respect to the in-group. No loose or neutral parts are permitted in a polarized fabric; all entries must be charged. Hirschhorn's ( I978) observation that stalemated systems are highly integrated and highly differentiated can now be explained. First, polarization and, thus, the in-group/out-group dynamics 
give the appearance of being highly integrated, and second, absorbing and permitting all kinds of variety gives the appearance of being highly differentiated.

\section{References}

Ackoff, R.L. and F.E. Emery. 1972. On Purposeful Systems. Chicago: Aldine Atherton. Angyal, A. I94I . Foundations for a Science of Personality. Cambridge, Mass.: Harvard University Press.

Ashby, W.R. 1960. Design for a Brain: The Origin of Adaptive Behavior. 2nd edition. New York: Wiley.

Babüroğlu, O.N. 1987. "A Theory of Stalemated Social Systems and Vortical Organizational Environments: The Turkish Experience and Beyond." Unpublished doctoral dissertation, University of Pennsylvania.

- 1991. "Is the End of Free Fall, Free Fall? The Focus of Adaptation in Vortical Environments." In The Cybernetics of Complex Systems, edited by Felix Geyer. Salinas, Calif.: Intersystems Publications.

Buckley, W.F. I968. "Society as a Complex Adaptive System." In Modern Systems Research for the Behavioral Scientist: A Sourcebook, edited by W.F. Buckley. Chicago: Aldine Atherton.

Burns, T. 1983. "Planning Networks and Network Agents: An Approach to Adaptive Community Governance." Unpublished doctoral dissertation, University of Pennsylvania.

Chandler, D.P. 1984. "Kampuchea: End Game or Stalemate?" Current History, 83: $4 \mathrm{I} 3$.

Crombie, A.D. 1972. "Planning for Turbulent Social Fields." Unpublished doctoral dissertation, Australian National University, Canberra. Vol. III, "Active Maladaptive Strategies," pp. I I 5-35.

Doyle, M.W. 1980. "Stalemate in the North-South Debate." World Politics.

Emery, F.E. I 977. Futures We Are In. Leiden: Martinus Nijhoff. Chapter 4, see Vol. II, "The Second Design Principle: Participation and Democratization of Work," pp. 2 I4-33. Chapter 2, see Vol. III, "Passive Maladaptive Strategies," pp. 99-I I4. Chapter 4, see Vol. III, "Active Adaptation: The Emergence of Ideal-Seeking Systems," pp. I47-69.

- 198I. "The Assembly Line: Its Logic and our Future." In Systems Thinking: Selected Readings, Vol. 2., edited by F.E. Emery. Harmondsworth: Penguin.

Emery, F.E. and M. Emery. I977. A Choice of Futures. Leiden: Martinus Nijhoff. Chapter 6, revised, see Vol. III, pp. I36-46.

- 1978. Searching: For New Directions, In New Ways . . . For New Times. In Management Handbook for Public Administrators, edited by J.W. Sutherland. New York: Van Nostrand Reinhold.

Emery, F.E. and E.L. Trist. I965. "The Causal Texture of Organizational Environments." Paper presented to the XVII International Psychology Congress, Washington, D.C., 1963. Reprinted in Sociologie du Travail, 4:64-75, I964; Human Relations, I8:2 I-32, I965; Vol. III, pp. 53-65.

- 1973. Towards a Social Ecology: Contextual Appreciation of the Future in the Present. London/New York: Plenum Press.

Esser, A. and W. Gray. 1983. "Science and Technology in the Service of Pluriculturalism." Man-Environment Systems. 


\section{Conceptual Developments}

Garnysz, C. 1984. "Polish Stalemate." Problems of Communism, 33:5I-59.

Gemmil, G. and C. Smith. I985. "A Dissipative Structure Model of Organization Transformation." Human Relations, 38:75 I-66.

Hannan, M.T. and J.H. Freeman. I978. "Internal Politics of Growth and Decline." In Environments and Organizations, edited by M.W. Meyer. San Francisco:

Hedberg, B.L., P.C. Nystorm and W.H. Starbuck. I976. "Camping in Seesaws: Prescriptions for a Self-Designing Organization." Administrative Science Quarterly, 2 I (March).

Hirschhorn, L. 1978. “The Stalemated Agency: A Theoretical Perspective and a Practical Proposal." Administration in Social Work, 2, 4 (Winter).

Hofer, E. 195I. The True Believer. New York: Harper and Row.

Hyman, A. 1984. "The Afghanistan Stalemate." The World Today.

Krepon, M. I984. Strategic Stalemate: Nuclear Weapons and Arms Control in American Politics. New York: St. Martin's Press.

Lifton, R.J. 1979. The Broken Connection: On Death and the Continuity of Life. New York: Simon and Schuster.

Linville, P.N. and E.E. Jones. I980. "Polarized Appraisals of Out-Group Members." Journal of Personality and Social Psychology, 38:689-703.

Maruyama, M. I976. "Toward Cultural Symbiosis." In Evolution and Consciousness: Human Systems in Transition, edited by E. Jantsch and C.H. Waddington. Reading, Mass.: Addison-Wesley.

- I982. "Beyond Management: The Shifting Focus of our Economic and Business Thinking." Cybernetics, 24:2 I 5-55.

Mason, D.S. 1985. "Stalemate and Apathy in Poland." Current History, November.

McCann, J.E. and W.J. Selsky. I984. "Hyperturbulence and the Emergence of Type V Environments." Academy of Management Review, 9:460-7I. Vol. III, pp. I85-202.

McDonald, R. I986. "Cyprus: Another Stalemate." The World Today, February, $42: 22$.

Metcalfe, L. I974. "Systems Models, Economic Models and the Causal Nature of Organizational Environments: An Approach to Macro-Organization Theory." Human Relations, 27:639-63.

- 1978. "Policy-Making in Turbulent Environments. In Interorganizational Policy-Making: Limits to Coordination and Central Control. Beverly Hills, Calif.: Sage.

. I982. "Self-Regulation, Crisis Management and Preventive Medicine: The Education of a U.K. Bank Supervisor.” Journal of Management Studies, I9:75-89.

Miller, D. 1977. "Common Syndromes of Business Failure." Business Horizons, November.

- I982. "Evolution and Revolution: A Quantum View of Structural Change in Organizations." Journal of Management Studies, 19: I3 I-5I.

Newcomb, T.M. I950. Social Psychology. New York: Dryden Press.

Nieburg, H.L. I969. Political Violence: The Behavioral Process. New York: St. Martin's Press.

Olson, M. I982. The Rise and Decline of Nations. New Haven, Conn.: Yale University Press.

Ozbekhan, H. I969. "Thoughts on the Emerging Planning Methodology." In Systems and Management Annual, edited by R.L. Ackoff. New York: Petrocelli Books.

- I97 I. "Planning and Human Action." In Hierarchically Organized Systems in Theory and Practice, edited by P.A. Weiss. New York: Hafner.

Perlmutter, H. and E. Trist. I986. "Paradigms for Societal Transition." Human Relations, 39: I-27. Vol. III, 650-74. 
Platt, H.D. I985. Why Companies Fail. Lexington, Mass.: D.C. Health.

Prigogine, I. I980. From Being to Becoming - Time and Complexity in the Physical Sciences. San Francisco: W.H. Freeman.

Prigogine, I. and G. Nicolis. I977. Self-Organization in Non-Equilibrium Systems. New York: Wiley.

Rokeach, M. I96o. The Open and Closed Mind. New York: Basic Books.

Schell, J. I984. "The Abolition.” New Yorker, January 2.

Schoderbeck, P.P., C.G. Schoderbeck and A.G. Kefalas. 1985. Management Systems. Texas: Business Publications.

Schon, D. 1971. Beyond the Stable State. New York: W.W. Norton.

Selsky, W.J. and J.E. McCann. I984. "Social Triage: An Emergent Response to Hyperturbulence." World Future Society Bulletin, I8: I -9.

Selznick, P. 1957. Leadership in Administration. New York: Row-Peterson.

Simmel, G. 1955. Conflict and the Web of Group Affiliation. New York: Free Press.

Sutton, R., K. Eisenhardt and J. Jucker. I986. "Managing Organizational Decline: Lessons from Atari." Organizational Dynamics (Spring).

Terreberry, S. 1968. "The Evolution of Organizational Environments." Administrative Science Quarterly, I2:590-6I3.

Tichy, N. 1983. "The Essentials of Strategic Change Management." Journal of Business Strategy, 3(4).

Toffler, A. I980. The Third Wave. New York: Morrow.

Trist, E.L. 1980. "The Environment and System-Response Capability." Futures (April).

- I992. "Andras Angyal and Systems Thinking." In Planning for Human Systems: Essays in Honor of Russell L. Ackoff, edited by J-M. Choukroun and R.M. Snow. Philadelphia: University of Pennsylvania Press.

Turner, T. 1985. "Zaire: Stalemate and Compromise." Current History, 84: 179-83.

Ward. B. 1978. "Can We Reach a 'Global Compact?'” In Patterns on Tomorrow: Strategies for a New International Order. New York: E.P. Dutton.

Whetten, D.A. I980. "Organizational Decline: A Neglected Topic in Organizational Science." Academy of Management Review, 5:577-88.

Williams, T. 1982. Learning to Manage our Futures: The Participative Redesign of Societies in Turbulent Transition.. New York: Wiley.

Wojciechowski, J. I983. "Implication of the Ecology of Knowledge for Multicultural Synergy.” Man-Environment Systems, I 3: I 83-92. 